\title{
The Dutch Parelsnoer Institute - Neurodegenerative diseases; methods, design and baseline results
}

\author{
Pauline Aalten ${ }^{1 *}$, Inez HGB Ramakers ${ }^{1}$, Geert Jan Biessels ${ }^{2}$, Peter Paul de Deyn ${ }^{3}$, Huiberdina L Koek², \\ Marcel GM OldeRikkert ${ }^{4}$, Ania M Oleksik ${ }^{5}$, Edo Richard ${ }^{6}$, Lieke L Smits', John C van Swieten ${ }^{8}$, Laura K Teune ${ }^{3}$, \\ Aad van der Lugt ${ }^{8}$, Frederik Barkhof ${ }^{7}$, Charlotte E Teunissen ${ }^{9}$, Nico Rozendaal ${ }^{1}$, Frans RJ Verhey ${ }^{1}$ and \\ Wiesje $\mathrm{M}$ van der Flier $^{7}$
}

\begin{abstract}
Background: The Parelsnoer Institute is a collaboration between 8 Dutch University Medical Centers in which clinical data and biomaterials from patients suffering from chronic diseases (so called "Pearls") are collected according to harmonized protocols. The Pearl Neurodegenerative Diseases focuses on the role of biomarkers in the early diagnosis, differential diagnosis and in monitoring the course of neurodegenerative diseases, in particular Alzheimer's disease. The objective of this paper is to describe the design and methods of the Pearl Neurodegenerative Diseases, as well as baseline descriptive variables, including their biomarker profile.

Methods: The Pearl Neurodegenerative Diseases is a 3-year follow-up study of patients referred to a memory clinic with cognitive complaints. At baseline, all patients are subjected to a standardized examination, including clinical data and biobank materials, e.g. blood samples, MRI and cerebrospinal fluid. At present, in total more than 1000 patients have been included, of which cerebrospinal fluid and DNA samples are available of 211 and 661 patients, respectively. First descriptives of a subsample of the data $(n=665)$ shows that patients are diagnosed with dementia (45\%), mild cognitive impairment (31\%), and subjective memory complaints (24\%).

Discussion: The Pearl Neurodegenerative Diseases is an ongoing large network collecting clinical data and biomaterials of more than 1000 patients with cognitive impairments. The project has started with data analyses of the baseline characteristics and biomarkers, which will be the starting point of future specific research questions that can be answered by this unique dataset.
\end{abstract}

Keywords: Dementia, Alzheimer's disease, Design, Biobank, Research infrastructure

\section{Background}

\section{The parelsnoer institute}

The Parelsnoer Institute (PSI; www.string-of-pearls.org) is a collaboration of the eight Dutch University Medical Centers (UMCs), designed to create an infrastructure for collection of clinical data and biomaterial from patients with chronic diseases. The conceptual starting point for PSI is the idea that clinical practice and research can mutually strengthen each other. By providing a harmonized infrastructure for the clinical evaluation of

\footnotetext{
* Correspondence: p.aalten@maastrichtuniversity.nl

${ }^{1}$ Alzheimer Center Limburg, School for Mental Health and Neuroscience (MHeNS), Maastricht University Medical Center, P.O. Box 616, 6200 MD Maastricht, The Netherlands

Full list of author information is available at the end of the article
}

patients, data collection and storage of data in a centralized database, PSI enables the use of multicenter clinical data to answer research questions targeted to improve patient care. PSI takes advantage of the Dutch context, where it is relatively easy to achieve nationwide coverage of disease populations because of the close connections. Initially, eight patient cohorts were created, symbolized by "Pearls". Besides Neurodegenerative diseases, in particular dementia, the Pearls include stroke, type 2 diabetes mellitus, hereditary colorectal cancer, inflammatory bowel diseases (Crohn's disease and ulcerative colitis), leukaemia, renal failure, and rheumatoid arthritis and arthrosis.

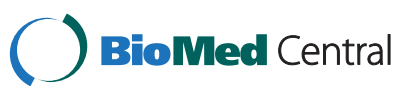

(c) 2014 Aalten et al.; licensee BioMed Central. This is an Open Access article distributed under the terms of the Creative Commons Attribution License (http://creativecommons.org/licenses/by/4.0), which permits unrestricted use, distribution, and reproduction in any medium, provided the original work is properly credited. The Creative Commons Public Domain Dedication waiver (http://creativecommons.org/publicdomain/zero/1.0/) applies to the data made available in this article, unless otherwise stated. 


\section{Neurodegenerative diseases}

Dementia is one of the major health care challenges of the 21st century. There are currently more than 35 million people affected with dementia worldwide, of which Alzheimer's disease (AD) is the most common type [1]. Other types of dementia include vascular dementia, dementia with Lewy bodies, frontotemporal dementia and more rare variants [2,3]. To date, there is no cure for $\mathrm{AD}$ or any of the other types of dementia. In fact, we are only just starting to understand the aetiology and disease course of these diseases. Research in $\mathrm{AD}$ has long time been hampered by the fact that neither plaques nor tangles (nor any of the proteins involved in other types of dementia) could be measured during life. The development of biomarker assays as diagnostic tests in cerebrospinal fluid (CSF) and amyloid imaging using PET has been a great breakthrough, together with structural imaging using MRI, acting as a catalyst for AD research. The biomarkers have been used to develop a hypothetical model, which serves to test hypotheses regarding the order of events leading to $\mathrm{AD}$ dementia $[4,5]$. In addition, there is increasing evidence that some biomarkers can be used as early diagnostic markers in the continuum of $\mathrm{AD}$. Results from several large studies have demonstrated that a combination of CSF biomarkers and neuroimaging measures is useful in predicting the likelihood of developing $\mathrm{AD}$ [6]. This has resulted in their incorporation in new diagnostic criteria, as a means to provide evidence for the presence of Alzheimer pathology [7-9]. It is now widely recognized that $\mathrm{AD}$ has a long pre-dementia stage, as brain changes start to accumulate as early as 15 to 20 years before dementia onset [10]. Mild cognitive impairment (MCI) refers to a stage where memory impairment can be objectified, but the patients' daily functioning is still intact. In university memory centres, patients with MCI have a mean annual conversion rate of $10 \%$ to dementia, mostly $\mathrm{AD}$ [11]. With the use of biomarkers, it is possible to make a better prediction of conversion to $A D$, though still far from perfect [12]. Preclinical AD is the proposed terminology to describe the stage when the earliest brain changes have begun, but there are no clinical signs yet [13].

\section{Aim pearl neurodegenerative diseases}

The aim of the Pearl Neurodegenerative diseases is to provide an infrastructure for the study of biomarkers for early diagnosis predicting clinical decline and incident dementia in those who are not demented yet, and for differential diagnosis and discriminating $\mathrm{AD}$ from other etiologies. The evaluation of a broad spectrum of patients, representing a tertiary memory clinic population, allows answering both questions. This is achieved by establishing a biobank containing blood, CSF, DNA with available extensive clinical phenotyping of patients, neuropsychological tests, and brain MRI. The data collection is completed by data from annual follow-up assessments.

In this paper, we describe the design and methods of the Pearl Neurodegenerative diseases as well as baseline descriptive variables. In addition, we extracted DNA and CSF from the biobank, and determined APOE genotype, and CSF concentrations of amyloid-beta 1-42 (ab42), total tau and tau phosphorylated at threonine 181 (ptau).

\section{Methods}

\section{Study design}

PSI is a collaboration of all eight UMCs in the Netherlands (University of Maastricht, Amsterdam (Free University and Amsterdam Medical Center), Rotterdam, Leiden, Groningen, Utrecht, and Nijmegen), and is jointly financed by the Dutch government and the eight Dutch UMCs. The Pearl "Neurodegenerative diseases" is a prospective, multi-center cohort study, focusing on tertiary memory clinic patients with cognitive problems including dementia. The memory clinics are embedded at the department of psychiatry ( 1 center), neurology ( 5 centers), or geriatrics ( 2 centers). Patients are enrolled from March 2009 and initially followed annually for two years. The goal was to include 100 patients per center, resulting in a database of 800 patients.

\section{Patients}

In order to include the whole cognitive spectrum from subjective cognitive complaints to dementia, broad inclusion criteria were chosen. Inclusion criteria included patients referred to a memory clinic for the evaluation of cognitive problems, with a clinical dementia rating scale (CDR) [14] score of 0, 0.5, or 1, and a Mini Mental State Examination (MMSE) [15] of 20 or higher. Exclusion criteria were: Normal Pressure Hydrocephalus, Morbus Huntington, recent Transient Ischemic Attack (TIA) or Cerebrovascular Accident (CVA) ( $<2$ years), TIA/CVA followed by cognitive decline (within three months), history of schizophrenia, bipolar disorder or psychotic symptoms not otherwise specified or previous treatment for these diseases, current major depressive disorder (DSM IV), cognitive problems due to alcohol abuse, brain tumor, epilepsy, encephalitis, mental incompetence for deciding participation, absence of a reliable informant, or the expectation that a follow-up assessment after one year was not possible.

\section{Baseline minimal dataset}

At baseline, each center collected a harmonized minimal dataset, consisting of variables highly relevant for the early diagnosis of neurodegenerative diseases. Data were collected according to Standard Operating Procedures (SOPs) specifically defined for the Pearl "Neurodegenerative diseases". 
The minimal dataset consisted of clinical data and a cognitive assessment. In addition, a MRI of the brain was made and blood samples and CSF samples (optional) were collected for biobanking purposes. Table 1 gives an overview of the data collection per assessment.

\section{Clinical data}

Data were collected on demographics, medical history, medication use, and family history from an open interview with both patient and caregiver. In addition, a clinician performed a physical examination. Finally, clinical assessment included several scales and questionnaires, as well as a standardized cognitive assessment.

\section{Demographic data}

Demographic variables included age, gender, educational level, ethnicity, and marital status.

\section{Physical examination}

The physical examination included the measurement of blood pressure, weight, height, gait disturbances, and extrapyramidal symptoms. In addition, data on smoking behavior, and alcohol consumption habits were collected.

\section{Syndromal diagnosis}

The diagnosis of dementia was based on DSM-IV criteria [16]. Etiological diagnoses were made according to standardized clinical criteria for AD (NINCDS-ADRDA criteria, $[16,17]$, vascular dementia (NINDS-AIREN criteria, [18], frontotemporal dementia [3], and Lewy body dementia [2].

\section{Medical history and medication use}

Data were collected on medical conditions, such as neurological problems, cardiovascular problems, cerebrovascular problems, endocrine diseases, psychiatric diseases, and somatic diseases. In addition, data on the current use of medication (name, dose, frequency, and Anatomical Therapeutic Chemical (ATC)-code) were collected.

Table 1 Flowchart data collection

\begin{tabular}{llll}
\hline & Baseline & 1-year FU & 2-year FU \\
\hline Informed consent & $X$ & & \\
Clinical data & $X$ & $X$ & $X$ \\
Cognitive assessment & $X$ & $X$ & $X$ \\
Scales and questionnaires & $X$ & $X$ & $X$ \\
Blood (serum and plasma) & $X$ & & $X$ \\
DNA & $X$ & & $X$ \\
MRI & $X$ & & \\
CSF (optional) & $X$ & & \\
\hline DNA: Deoxyribonucleic Acid, & MRgnet & & \\
\hline
\end{tabular}

DNA: Deoxyribonucleic Acid, MRI: Magnet Resonance Imaging, CSF: Cerebrospinal fluid.

\section{Family history}

Data were collected on the family history of diagnoses of dementia, Parkinsonism, and Amyotrophic Lateral Sclerosis, including the number of first and second-degree relatives, the specification of the relatives, and their age at time of diagnosis.

\section{Scales and questionnaires}

The CDR, rated by the physician, provided a global rating of dementia severity. The 15-item Geriatric Depression Scale (GDS-15) [19] and the Euro-Quality of life-5 Dimensions [20] were used to provide self-reported information about depressive symptoms and quality of life. The 4-item questionnaire on Subjective Cognitive Functioning (SCF) gave information about the patient's experience of his change in cognitive functioning. A semi-structured interview with a familiar caregiver provided information about the presence of neuropsychiatric symptoms and the daily functioning. The frequency and severity of neuropsychiatric symptoms were measured using the Neuropsychiatric Inventory (NPI) [21]. Basic and instrumental activities in daily life were assessed with the Disability assessment for Dementia (DAD) [22].

\section{Cognitive assessment}

Data about the start and course of the cognitive complaints were collected. The cognitive assessment consisted of a standardized battery of cognitive tests. All tests were performed according to the SOP for cognitive assessment. The tests were harmonized across all centers. An overview of the tests used and their corresponding cognitive domains is presented in Box 1.

\section{Box 1 Standardized cognitive test battery}

\begin{tabular}{|c|c|}
\hline Test & Cognitive domain(s) \\
\hline Mini Mental State Examination $^{1}$ & Global cognition \\
\hline $\begin{array}{l}15 \text { Word-Auditory Verbal Learning } \\
\text { Test }^{2}\end{array}$ & Episodic memory \\
\hline Visual Association Test, short version ${ }^{3}$ & Implicit associative visual learning \\
\hline $\begin{array}{l}\text { Digit-Span of the WAIS III (forward } \\
\text { and backward) }{ }^{4}\end{array}$ & Working memory \\
\hline Fluency, 60 seconds (animals) ${ }^{5}$ & $\begin{array}{l}\text { Verbal word fluency/semantic } \\
\text { memory }\end{array}$ \\
\hline $\begin{array}{l}\text { Letter Digit Substitution Test, } \\
60 \text { seconds }^{6}\end{array}$ & Information processing speed \\
\hline $\begin{array}{l}\text { Stroop Color Word Test }(\mathrm{SCWT})^{7} \text {, } \\
10 \times 10 \text { items, } 4 \text { colors }\end{array}$ & $\begin{array}{l}\text { Information processing speed, } \\
\text { attention and respons inhibition/ } \\
\text { executive functioning }\end{array}$ \\
\hline Trail Making Test (TMT) (Part A and B) ${ }^{8}$ & $\begin{array}{l}\text { Information processing speed, } \\
\text { attention and concept shifting/ } \\
\text { executive functioning }\end{array}$ \\
\hline $\begin{array}{l}\text { Optional: dot counting and } \\
\text { incomplete letters of the Visual } \\
\text { Object and Space Perception Battery }\end{array}$ & Visual perception \\
\hline
\end{tabular}

References: 1 [15]; 2 [23,24]; 3 [25]; 4 [26]; 5 [27]; 6 [28]; 7 [29,30]; 8 [31]. 


\section{Biobank}

MRI

A standardized MRI protocol was defined in the SOP for brain imaging. Box 2 gives an overview of the MRI sequences included in the protocol. Acquisition of the MR images was performed at each individual site using MR systems operating at 1.5 or 3.0 Tesla. For each individual site, scanning was performed using the same scanner and headcoil throughout the study. After acquisition, scans were anonymized according to predefined and centralized guidelines. Pseudonymised data were subsequently transferred to the Image Analysis Centre (IAC) of the VUmc in Amsterdam, the Netherlands. The IAC collected, reviewed and stored the MR images. As part of the quality control (e.g. being compared by the local dummy scan), each MRI was centrally read by a neuroradiologist or trained rater and rated according to a number of basic visual rating scales: Medial Temporal Lobe Atrophy (MTA) [32], Global Cortical Atrophy (GCA) [33], White Matter Hyperintensities (WMH) [34]. In addition, lacunar infarcts, cortical infarcts, and microbleeds were counted.

\section{Blood}

Samples of venous blood (10 cc clotted blood for serum and 6 cc EDTA blood for plasma) were collected. Samples were aliquoted into $0.5 \mathrm{cc}$ samples and stored at $-80^{\circ} \mathrm{C}$ in each local biobank.

\section{DNA}

6 cc EDTA whole blood was collected for DNA extraction. DNA was isolated at each individual site. DNA isolation was performed robotically, based on a salting out method. After isolation and a quality control, the DNA was stored in four cups at $-80^{\circ} \mathrm{C}$. Isolated DNA was taken from the local biobanks and transported to the department of Clinical Genetics of the Maastricht University Medical Center. Apolipoprotein E (APOE) genotype was determined on genomic DNA using the polymerase chain reaction (PCR) technique [35]. Genotyping was done blinded for all clinical data.

\section{CSF}

CSF was collected via a lumbar puncture in the intervertebral space at level L3/L4 or L4/L5. CSF was collected and stored in polypropylene tubes. Three cc of CSF was aliquoted in $0.5 \mathrm{cc}$ samples and stored at $-80^{\circ} \mathrm{C}$ until analysis.

CSF samples were transported to the department of Clinical Chemistry of the VUmc Amsterdam. The samples were analyzed all at once, using the same batch of reagents. Ab42, tau, and ptau concentrations were measured using commercially available single-parameter ELISA methods (respectively Innotest ${ }^{\circ}$ beta-amyloid (1-42) and
Innotest ${ }^{\circledR}$ hTAU-Ag; Innogenetics, Ghent, Belgium). CSF analyses were done blinded for all clinical data.

\section{Follow-up assessment}

One and two years after baseline, patients were invited for a follow-up assessment. At this time, the same clinical and cognitive data were obtained. In addition, the follow-up assessment two years after baseline also included the collection of blood samples and an MRI of the brain (Table 1). At follow-up, the course of cognitive problems was investigated and the syndromal and etiological diagnosis of each patient was based on the standardized criteria used at baseline.

Subjects who were not available for a follow-up assessment were contacted by telephone, using a standardized case record form (CRF) for telephone interview. This CRF included information on survival, the CDR, information about the reason for not participating in the follow-up assessment, the course of the cognitive complaints, interference with daily living, reasons for eventual hospital visitations, and whether a diagnosis of dementia was made since the previous measurement. Recently, the consortium has prolonged the clinical follow-up to at least three years, so the study is ongoing.

\section{Data collection, processing and storage}

At baseline and follow-up, data are collected in a CRF based on SOPs. Data of the CRFs are locally stored in each center, based on a centrally defined Process Information Model (PIM) (www.string-of-pearls.org). The use of a PIM guarantees harmonized data collection across UMCs, and across diseases for shared variables, like demographics and medication use. After pseudonymisation, data were uploaded to a central data system. At a central level, PSI facilitates collaborative research and delivers a standardized Central Infrastructure, in which all clinical data collected by the UMCs are managed at one location.

Biological samples were processed and stored in each local biobank according to the SOP for biomaterials. For standardized analysis, biological samples were transported on dry ice to central laboratories according to the SOP for the transportation of biomaterials.

\section{Ethical considerations}

The Medical Ethics Review Committee of the VU University Medical Center performed central approval of the study. All local Medical Ethical Committees approved the local performance of the study. The research is performed according to the principles of the Declaration of Helsinki (October 2008, www.wma.net) and in accordance with the Medical Research Involving Human Subjects Act and codes on 'good use' of clinical data and biological samples as developed by the Dutch Federation of Medical 
1.

2.

3.

4.

5.

6.

\section{Sagittal 3D T1-weighted gradient-echo sequence (6-9 $\mathrm{min})$.}

E.g. MP-RAGE, SPGR, FFE

Correction for non-linear gradients (if applicable)

TE and TR according to local settings- giving good gray matter - white matter contrast

Slab thickness $180 \mathrm{~mm}, 180$ partitions, $1.0 \mathrm{~mm}$ effective slice thickness

In-plane resolution $1.0 \mathrm{~mm}$

2D T2* gradient-echo sequence (3-5 $\mathrm{min}$ )

e.g. FLASH/FFE/SPGR, or (EPI-) SWI to obtain dark tissue background susceptible to T2* contrast -such as microbleedings. $T R \geq 500 \mathrm{~ms}, \mathrm{TE} \geq 20 \mathrm{~ms}$. Flip angle 20 degrees

Slice thickness $3 \mathrm{~mm}$, no gap

Number of slices 48

In-plane resolution 0.5 - $1.0 \mathrm{~mm}$

2D T2-weighted FLAIR turbo/fast spin-echo (3-5 min)

TR 8,000 - 12,000 ms, TE 100-150 ms, TI 2,200 - 2,800 ms

Slice thickness $3 \mathrm{~mm}$, no gap

Number of slices 48

In-plane resolution 0.5 - $1.0 \mathrm{~mm}$

\section{D T2-weighted turbo/fast spin-echo (3-5 $\mathrm{min}$ )}

TR 2,000 - 4,000 ms, TE 80-120 ms

Slice thickness $3 \mathrm{~mm}$, no gap

Number of slices 48

In-plane resolution $0.5-1.0 \mathrm{~mm}$

2D Diffusion weighted imaging/EPI (30 sec-1 $\mathrm{min}$ )

Parallel Imaging on if possible (mandatory for $3 \mathrm{~T}$ )

TR 3,000-6,000 ms, TE 90-130 ms

Slice thickness < $5 \mathrm{~mm}$, gap 10-30\%

In plane resolution $2 \mathrm{~mm}$ b value (0/500/1000) or b value (0/900) or b value $(0 / 1000) \mathrm{s} / \mathrm{mm}^{2}$.

5b. Include online calculated ADC maps if possible.

2D Diffusion tensor imaging (optional) (6-8 min)

Parallel Imaging on if possible (mandatory for $3 \mathrm{~T}$ )

TR 8,000-14,000 ms, TE 80-100 ms

Number of slices $56-70$ slices

In-plane resolution $2.0-2.5 \mathrm{~mm}$.

$30-60$ diffusion weighted directions with $b=1000 \mathrm{~s} / \mathrm{mm}^{2}, 5-6$ scans with $b=0 \mathrm{~s} / \mathrm{mm}^{2}$

Fat suppression ON

2D Resting state fMRI (optional) (7-10 min)

\subsection{Tesla scanner:}

TR 1,800-2,200 ms, TE 30-40 ms, Flip Angle 80 degrees

Slice thickness $2.0-2.5 \mathrm{~mm}$, gap 10\%

Number of slices $38-54$

In-plane resolution 2.0 - $2.3 \mathrm{~mm}$

Number of volumes 200 (excluding run-in scans)

\subsection{Tesla scanner:}

TR 2,200-3,000 ms, TE 40-60 ms. Flip Angle 90 degrees

Slice thickness 2.5-3.0 mm, gap 10\% 
Box 2 MRI protocol (Continued)

\author{
Number of slices $30-38$ \\ In-plane resolution $2.5-3.3 \mathrm{~mm}$ \\ Number of volumes 200 (excluding run-in scans)
}

All scans have full brain coverage except DTI, which has coverage of at least $140 \mathrm{~mm}$ and resting state fMRI that had coverage of at least $105 \mathrm{~mm}$. All scans were in the transverse orientation except the 3D T1w gradient echo sequence, which was in the sagittal orientation.

Scientific Societies. In addition, PSI has provided a regulatory framework in which ethical and legal rules and guidelines have been described. For guaranteeing the privacy of the patients' data and biomaterials, a pseudonymisation service is delivered by a Trusted Third Party. All patients gave written informed consent.

\section{Results}

\section{Preliminary baseline results}

In total more than 1000 patients have been included, of which of a subsample of 665 patients, data were available for the present analysis. Data from this subsample of patients were at present available and could be extracted from the local UMCs and combined in one dataset, according to the regulatory framework of PSI. Slightly less than half of the patients were female. Average age was $70 \pm 10$ years old (Table 2). MMSE and CDR values show that in the majority of patients cognition was mildly impaired (Table 2). In line with this, the syndrome diagnosis was distributed as follows: subjective memory complaints (24\%), MCI (31\%), and dementia (45\%).

APOE genotype measurement was available for 661 (99\%) patients and CSF biomarkers for 211 (32\%) patients. Table 3 shows that patients with dementia were more likely to be APOE e4 positive than patients with subjective complaints, with patients with $\mathrm{MCI}$ in between. Mean CSF concentrations of ab42 were lower while CSF concentrations of (p)tau were higher in dementia patients than in patients with subjective complaints. For all CSF biomarkers, the mean concentrations of $\mathrm{MCI}$ were intermediate.

\section{Discussion}

The Pearl Neurodegenerative Diseases is a nationwide network enabling centralized and uniform collection of clinical data, blood, CSF and MRI of the brain in

Table 2 Basic demographic and clinical variables of subsample

\begin{tabular}{ll}
\hline $\mathbf{N}$ & $\mathbf{6 6 5}$ \\
\hline Gender, F & $276(42 \%)$ \\
Age, years & $70 \pm 10 ;<65$ year: $31 \%$ \\
MMSE & $26 \pm 3$ \\
CDR; $0 ; 0.5 ; 1$ & $21 \% ; 51 \% ; 28 \%$ \\
\hline
\end{tabular}

Data are presented as $\mathrm{n}(\%)$ or mean $\pm \mathrm{sd}$. patients from tertiary memory clinics. To date, this has resulted in harmonization of data collection across centers and in the inclusion of more than 1000 patients with cognitive complaints, MCI or dementia. The current preliminary biomarker study has shown feasibility of collecting biomaterial from local biobanks for central analysis and coupling with phenotypical data, showing the potential of our data set.

The infrastructure of the Pearl Neurodegenerative Diseases, taking advantage of the PSI Central Infrastructure and regulatory framework, provides an excellent starting point for future research, including collaborations with other (inter)national projects focusing on neurodegenerative diseases. The dataset makes it possible to perform nationwide research into early diagnosis of neurodegenerative diseases, in particular AD. The uniqueness of this data set lies in the national coverage as our consortium includes all Dutch UMCs. Among the most important achievements until now is the harmonization of diagnostic procedures across academic memory centers. The use of SOP's and therefore a strict uniform data collection guarantees high quality of the data. We already see that other local memory clinics start to adopt the PSI-procedures, resulting in further standardization of diagnostics across the country and opening up further possibilities for collaborating in research projects.

The infrastructure of the Pearl Neurodegenerative Diseases is used as a framework for other studies, including

Table 3 APOE and CSF biomarker baseline descriptives by syndrome diagnosis

\begin{tabular}{llll}
\hline & Subjective complaints & MCI & Dementia \\
\hline APOE genotype & & & \\
APOE N & 159 & 208 & 294 \\
e4 noncarrier & $96(60 \%)$ & $97(47 \%)$ & $137(47 \%)$ \\
e4 heterozygous & $51(32 \%)$ & $90(43 \%)$ & $124(42 \%)$ \\
e4 homozygous & $12(8 \%)$ & $19(9 \%)$ & $29(10 \%)$ \\
CSF biomarkers & & & \\
CSF biomarker N & 60 & 67 & 84 \\
Amyloid-beta 1-42 & $817 \pm 252$ & $692 \pm 290$ & $610 \pm 258$ \\
Total tau & $286 \pm 170$ & $473 \pm 257$ & $514 \pm 277$ \\
Ptau & $38 \pm 18$ & $53 \pm 26$ & $57 \pm 26$ \\
\hline
\end{tabular}

Data are presented as mean \pm sd. Please note that while raw CSF biomarker values are presented, statistical analyses were performed using log-transformed values. 
the Dutch LeARN AD study [36]. In addition, both clinical data and biomaterial (specifically CSF) have already been incorporated in large international consortia (BIOMARKAPD; EMIF-AD) in the context of the Joint Programming of Neurodegenerative Diseases (JPND; www.neurodegene rationresearch.eu) and Innovative Medicines Initiative (IMI; www.imi.europa.eu) of the European Union.

Several other multicentre initiatives have collected data to study the value of new biomarkers for early identification of $\mathrm{AD}$ and related disorders. The Alzheimer's Disease Neuroimaging Initiative (ADNI) in North America aims to identify neuroimaging measures and biomarkers associated with cognitive and functional changes in healthy elderly subjects and in subjects who have $\mathrm{MCI}$ and $\mathrm{AD}$ (www.adni-info.org). The Australian Imaging, Biomarkers and Lifestyle (AIBL) study of ageing aims to study biomarkers, cognitive characteristics and health and lifestyle factors determine AD (www.aibl.csiro.au). The Swedish Brain Power Network (www.swedishbrainpower.se) aims to enhance early diagnosis, treatment and care for patients with neurodegenerative diseases, including AD, Parkinson's Disease and amyotrophic lateral sclerosis. The Pearl Neurodegenerative Diseases adds to these other programs by firmly consolidating research in a clinical setting. The implementation of SOPs in clinical routine guarantees maximally efficient use of data and is thought to allow swift feedback of research results into clinical practice.

Among the limitations of the Pearl Neurodegenerative diseases is the potential referral bias as a consequence of inclusion of patients at tertiary UMC. The study results are generalizable to a population of patients referred to an academic memory clinic, but not to patients referred to a general practitioner, or any other community hospital or from the general population. Our sample provides a good reflection however of the patient population for which biomarkers might have high relevance. In addition, we included a broad range of patients, covering the continuum of cognitive decline from subjective complaints until the clinical diagnosis of dementia, but not healthy controls. One might argue, however, that for the aims of the present Pearl Neurodegenerative Diseases that the comparison of patients with dementia with patients with subjective complaints has more clinical relevance than comparing patients with dementia to healthy controls.

Based on our recent experience, we have continued patient inclusion to enlarge our data set. In addition, the consortium has decided to prolong clinical follow-up to at least three years, to allow the study of biomarkers in relation to long-term follow-up.

\section{Conclusion}

In conclusion, the deep phenotyping in combination with longitudinal data collection, the multi-center set up, and the firm basis in regular patient care, resulting in a sample of real life patients, rather than a highly selected research sample, make our sample attractive for future studies aiming to develop diagnostic biomarkers, prognostic biomarkers, 'theranostic' (i.e. predicting response to therapy) biomarkers and biomarkers aiming to monitor disease progression. As such, the Pearl Neurodegenerative Diseases forms an ideal real life sample to host studies aiming to improve trial design and to validate new targets of therapy.

\section{Competing interests}

The work described in this study was carried out in the context of the Parelsnoer Institute (PSI: www.string-of-pearls.org). PSI is part of and funded by the Dutch Federation of University Medical Centers and has received initial funding from the Dutch Government (from 2007-2011).

The authors declare that they have no competing interests. None of the authors have direct or indirect relationships with the sponsor.

\section{Authors' contributions}

PA: study design, data collection, study coordination, wrote manuscript. IR: data collection, local study coordination, wrote manuscript. GJB: study design, data collection, local study coordination. PPD: data collection, local study coordination. HLK: data collection, local study coordination. MOR: study design, data collection, local study coordination. AO: data collection, local study coordination. ER: study design, data collection, local study coordination. LS: data collection, local study coordination. JvS: study design, data collection, local study coordination. AL: data collection, local study coordination. FB: responsible for MRI analyses. CT: responsible for CSF analyses. NR: data manager. FV: study design, data collection, study coordination. WF: study design, data collection, study coordination, wrote manuscript. All authors read and approved the final manuscript.

\section{Author details}

${ }^{1}$ Alzheimer Center Limburg, School for Mental Health and Neuroscience (MHeNS), Maastricht University Medical Center, P.O. Box 616, 6200 MD Maastricht, The Netherlands. ${ }^{2}$ Departments of Neurology and Geriatrics, University Medical Center Utrecht, Utrecht, The Netherlands. ${ }^{3}$ Department of Neurology, Alzheimer Research Cente, University Medical Center Groningen, Utrecht, The Netherlands. ${ }^{4}$ Alzheimer Center Nijmegen, Radboud University Medical Center Nijmegen, Nijmegen, The Netherlands. ${ }^{5}$ Department of Gerontology and Geriatrics, Leiden University Medical Center, Leiden, The Netherlands. ${ }^{6}$ Department of Neurology, Academic Medical Center Amsterdam, Amsterdam, The Netherlands. ${ }^{7}$ Alzheimer Center Amsterdam, VU Medical Center Amsterdam, Amsterdam, The Netherlands. ${ }^{8}$ Departments of Neurology and Radiology, Erasmus Medical Center, Rotterdam, The Netherlands. ${ }^{9}$ Department of Clinical Chemistry, Neurochemistry Laboratory and Biobank, VU Medical Center Amsterdam, Amsterdam, The Netherlands.

Received: 4 November 2014 Accepted: 16 December 2014

Published online: 31 December 2014

\section{References}

1. International World Health Organization: Dementia: A Public Health Priority. 2012.

2. McKeith IG, Galasko D, Kosaka K, Perry EK, Dickson DW, Hansen LA, Salmon DP, Lowe J, Mirra SS, Byrne EJ, Lennox G, Quinn NP, Edwardson JA, Ince PG, Bergeron C, Burns A, Miller BL, Lovestone S, Collertan D, Jansen EN, Ballard C, de Vos RA, Wilcock GK, Jellinger KA, Perry RH: Consensus guidelines for the clinical and pathologic diagnosis of dementia with Lewy bodies (DLB): report of the consortium on DLB international workshop. Neurology 1996, 47(5):1113-1124.

3. Neary D, Snowden JS, Gustafson L, Passant U, Stuss D, Black S, Freedman M, Kertesz A, Robert PH, Albert M, Boone K, Miller BL, Cummings J, Benson DF: Frontotemporal lobar degeneration: a consensus on clinical diagnostic criteria. Neurology 1998, 51(6):1546-1554.

4. Jack CR Jr, Knopman DS, Jagust WJ, Petersen RC, Weiner MW, Aisen PS, Shaw LM, Vemuri P, Wiste HJ, Weigand SD, Lesnick TG, Pankratz VS, Donohue MC, Trojanowski JQ: Tracking pathophysiological processes in Alzheimer's disease: an updated hypothetical model of dynamic biomarkers. Lancet Neurol 2013, 12(2):207-216. 
5. Jack CR Jr, Knopman DS, Jagust WJ, Shaw LM, Aisen PS, Weiner MW, Petersen RC, Trojanowski JQ: Hypothetical model of dynamic biomarkers of the Alzheimer's pathological cascade. Lancet Neurol 2010, 9(1):119-128.

6. Petersen RC: Alzheimer's disease: progress in prediction. Lancet Neurol 2010, 9(1):4-5.

7. Albert MS, DeKosky ST, Dickson D, Dubois B, Feldman HH, Fox NC, Gamst A, Holtzman DM, Jagust WJ, Petersen RC, Snyder PJ, Carrillo MC, Thies B, Phelps CH: The diagnosis of mild cognitive impairment due to Alzheimer's disease: recommendations from the National Institute on Aging-Alzheimer's Association workgroups on diagnostic guidelines for Alzheimer's disease. Alzheimers Dement 2011, 7(3):270-279.

8. Dubois B, Feldman HH, Jacova C, Cummings JL, Dekosky ST, Barberger-Gateau P, Delacourte A, Frisoni G, Fox NC, Galasko D, Gauthier S, Hamel H, Jicha GA, Meguro K, O'Brien J, Pasquier F, Robert P, Rassor M, Salloway S, Sarazin M, de Souza LC, Stern Y, Visser PJ, Scheltens P: Revising the definition of Alzheimer's disease: a new lexicon. Lancet Neurol 2010, 9(11):1118-1127.

9. McKhann GM, Knopman DS, Chertkow H, Hyman BT, Jack CR Jr, Kawas CH, Klunk WE, Koroshetz WJ, Manly JJ, Mayeux R, Mohs RC, Morris JC, Rossor MN, Scheltens P, Carrillo MC, Thies B, Weintraub S, Phelps CH: The diagnosis of dementia due to Alzheimer's disease: recommendations from the National Institute on Aging-Alzheimer's Association workgroups on diagnostic guidelines for Alzheimer's disease. Alzheimers Dement 2011, 7(3):263-269.

10. Bateman RJ, Xiong C, Benzinger TL, Fagan AM, Goate A, Fox NC, Marcus DS, Cairns NJ, Xie X, Blazey TM, Holtzman DM, Santacruz A, Buckles V, Oliver A, Moulder K, Aisen PS, Ghetti B, Klunk WE, McDade E, Martins RN, Masters CL, Mayeux R, Ringman JM, Rossor MN, Schofield PR, Sperling RA, Salloway S, Morris JC: Clinical and biomarker changes in dominantly inherited Alzheimer's disease. N Engl J Med 2012, 367(9):795-804.

11. Bruscoli $\mathrm{M}$, Lovestone $\mathrm{S}$ : Is $\mathrm{MCl}$ really just early dementia? A systematic review of conversion studies. Int Psychogeriatr 2004, 16(2):129-140.

12. Mattsson $N$, Zetterberg $H$, Hansson $O$, Andreasen $N$, Parnetti L, Jonsson M, Herukka SK, van der Flier WM, Blankenstein MA, Ewers M, Richi K, Kaiser E, Verbeek M, Tsolaki M, Mulugeta E, Rosen Em Aarsland D, Visser PJ, Schroder J, Marcusson J, de Leon M, Hampel H, Scheltens P, Pirttila T, Wallin A, Jonhagen ME, Mintham L, Winblad B, Blennow K: CSF biomarkers and incipient Alzheimer disease in patients with mild cognitive impairment. JAMA 2009, 302(4):385-393.

13. Sperling RA, Johnson KA: Dementia: new criteria but no new treatments. Lancet Neurol 2012, 11(1):4-5.

14. Morris JC: The Clinical Dementia Rating (CDR): current version and scoring rules. Neurology 1993, 43(11):2412-2414.

15. Folstein MF, Folstein SE, McHugh PR: "Mini-mental state". A practical method for grading the cognitive state of patients for the clinician. J Psychiatr Res 1975, 12(3):189-198.

16. APA: Diagnostic and Statistical Manual of Mental Disorders IV (IVth edn). Washington DC: American Psychiatric Association; 1994.

17. McKhann G, Drachman D, Folstein M, Katzman R, Price D, Stadlan EM: Clinical diagnosis of Alzheimer's disease: report of the NINCDS-ADRDA Work Group under the auspices of Department of Health and Human Services Task Force on Alzheimer's Disease. Neurology 1984 34(7):939-944.

18. Roman GC, Tatemichi TK, Erkinjuntti T, Cummings JL, Masdeu JC, Garcia JH, Amaducci L, Orgogozo JM, Brun A, Hofman A, et al: Vascular dementia: diagnostic criteria for research studies. Report of the NINDS-AIREN International Workshop. Neurology 1993, 43(2):250-260.

19. Almeida OP, Almeida SA: Short versions of the geriatric depression scale: a study of their validity for the diagnosis of a major depressive episode according to ICD-10 and DSM-IV. Int J Geriatr Psychiatry 1999, 14(10):858-865.

20. Brooks R: EuroQol: the current state of play. Health Policy 1996, 37(1):53-72.

21. Cummings $\mathrm{J}$ : The Neuropsychiatric Inventory: assessing psychopathology in dementia patients. Neurology 1997, 48(5 Suppl 6):S10-S16.

22. Gelinas I, Gauthier L, McIntyre M, Gauthier S: Development of a functional measure for persons with Alzheimer's disease: the disability assessment for dementia. Am J Occup Ther 1999, 53(5):471-481.

23. Brand $\mathrm{N}$, Jolles J: Learning and retrieval rate of words presented auditorily and visually. J Gen Psychol 1985, 112(2):201-210.

24. Rey A: L'examen clinique en psychology. Oxford England: Presses Universitaries De France; 1958.
25. Lindeboom J, Schmand B, Tulner L, Walstra G, Jonker C: Visual association test to detect early dementia of the Alzheimer type. J Neurol Neurosurg Psychiatry 2002, 73(2):126-133.

26. Wechsler D: Wechsler Memory Scale - 3rd edition: Administration and Scoring Manual. San Antonio: The Psychological Corporation; 1997.

27. Lezak M: Neuropsychological Assessment. 3rd edition. New York: Oxford University Press; 1995.

28. van der Elst W, van Boxtel MP, van Breukelen GJ, Jolles J: The Letter Digit Substitution Test: normative data for 1,858 healthy participants aged 24-81 from the Maastricht Aging Study (MAAS): influence of age, education, and sex. J Clin Exp Neuropsychol 2006, 28(6):998-1009.

29. Stroop JR: Studies of interference in serial verbal reactions. J Exp Psychol 1935, 18(6):643-662.

30. Van der Elst W, Van Boxtel MP, Van Breukelen GJ, Jolles J: Detecting the significance of changes in performance on the Stroop Color-Word Test, Rey's Verbal Learning Test, and the Letter Digit Substitution Test: the regression-based change approach. J Int Neuropsychol Soc 2008, 14(1):71-80

31. Reitan RM: Validity of the Trail Making Test as an indicator of organic brain damange. Percept Mot Skills 1958, 8:271-276.

32. Scheltens $P$, Leys $D$, Barkhof F, Huglo D, Weinstein HC, Vermersch $P$, Kuiper $M$ Steinling M, Wolters EC, Valk J: Atrophy of medial temporal lobes on MRI in "probable" Alzheimer's disease and normal ageing: diagnostic value and neuropsychological correlates. I Neurol Neurosurg Psychiatry 1992, 55(10):967-972.

33. Pasquier F, Leys D, Weerts JG, Mounier-Vehier F, Barkhof F, Scheltens P: Inter- and intraobserver reproducibility of cerebral atrophy assessment on MRI scans with hemispheric infarcts. Eur Neurol 1996, 36(5):268-272.

34. Fazekas F, Barkhof F, Wahlund LO, Pantoni L, Erkinjuntti T, Scheltens P, Schmidt R: CT and MRI rating of white matter lesions. Cerebrovasc Dis 2002, 13(Suppl 2):31-36.

35. Bekers O, op den Buijsch RA, de Vries JE, Wijnen PA, van Dieijen-Visser MP: Capillary electrophoretic detection in apolipoprotein E genotyping. Electrophoresis 2002, 23(12):1878-1881.

36. Handels RL, Aalten P, Wolfs CA, OldeRikkert M, Scheltens P, Visser PJ, Joore MA, Severens JL, Verhey FR: Diagnostic and economic evaluation of new biomarkers for Alzheimer's disease: the research protocol of a prospective cohort study. BMC Neurol 2012, 12:72.

\section{Submit your next manuscript to BioMed Central and take full advantage of:}

- Convenient online submission

- Thorough peer review

- No space constraints or color figure charges

- Immediate publication on acceptance

- Inclusion in PubMed, CAS, Scopus and Google Scholar

- Research which is freely available for redistribution

Submit your manuscript at www.biomedcentral.com/submit
C Biomed Central 